\title{
Influence of digitalization on the development of social entrepreneurship in the regions of Russian Federation
}

\author{
Anna Veretennikova ${ }^{1,2,3}$, Kseniya Kozinskaya ${ }^{2,3, *}$ \\ ${ }^{1}$ Ural Institute of Management of the Russian Presidential Academy of National Economy and Public \\ Administration, 620144, ul. 8 Marta, 66, Ekaterinburg, Russia \\ ${ }^{2}$ Institute of Economics of the Urals Branch of the Russian Academy of Sciences, 620014, ul. \\ Moskowskaya, 29, Ekaterinburg, Russia \\ ${ }^{3}$ The Ural Federal University the Ural Federal University named after the first President of Russia \\ B. N. Yeltsin, Ekaterinburg, Russia
}

\begin{abstract}
The development of social entrepreneurship as a relatively new form of solving social problems depends on many factors, particularly on the institutional environment and its digitalization. Information processing systems and various activities associated with digital technologies affect almost all aspects of economic activity. This study aims to analyze and substantiate the impact of digital transformation processes on social enterprises in the regions of the Russian Federation. Regression and correlation analysis was used as a research method. In the course of testing the hypothesis about the influence of the digital component on the development of social entrepreneurship, the importance of investment in informatization and communications and the share of the population using the Internet in a particular region are shown.
\end{abstract}

\section{Introduction}

Over the past two decades, social entrepreneurship has attracted more and more interest worldwide, including in scientific research. This phenomenon can be explained by economic, social, and political changes aimed at increasing the efficiency of resources at various levels of government. On the one hand, both at the regional and national and the global level, there is an increase in the need for solving social problems. On the other hand, new alternative ways of solving these problems are being formed by increasing the activity of civil society. This trend stimulates interest in the development of social entrepreneurship as a new form of entrepreneurship and a way to solve socially significant problems facing society. The key feature of this type of activity is the so-called "hybrid value", which implies both social and commercial significance of the proposed solutions.

The concept of social entrepreneurship for Russia is relatively new - it is not more than 20 years old. Despite all the practical importance of social entrepreneurship, there are still disagreements regarding the definition of this phenomenon. The phenomenon of social

* Corresponding author: ksush1@yandex.ru 
entrepreneurship is most fully revealed in the study of social entrepreneurship in Russia by A.A. Moskovskaya, which uses the approach of the Anglo-American tradition [1]. The definition used by A.A. Moskovskaya is based on the formulation of Kim Alter [2]. It reads as follows: "Social entrepreneurship is a new way of socio-economic activity, which combines the social purpose of an organization with entrepreneurial innovation and the achievement of sustainability" [1].

In Russia, only in 2019 was law 245-FA on social entrepreneurship adopted, which defined this type of activity. "Social entrepreneurship is an entrepreneurial activity aimed at achieving socially useful goals, contributing to the solution of social problems of citizens and society and carried out by the conditions provided for in Part 1 of Article 24.1 of Federal Law No. 245-FA." A social enterprise is defined as a small or medium-sized business entity carrying out activities in social entrepreneurship.

Thus, since 2020, an organization with the status of "Social Enterprise" has appeared. However, according to the Agency for Strategic Initiatives, only $1 \%$ of small and mediumsized companies are engaged in social entrepreneurship in Russia, while in Europe, this figure reaches $25 \%$ [3]. By the end of 2021, there are more than 2500 organizations with "social entrepreneurship" status, while the organizational and legal form of this enterprise individual entrepreneur or any other type of organization does not matter. These socially oriented organizations received this status in 2020 during the first wave of registration. In addition, the adoption of the law contributed to the development of various forms of financial support for social entrepreneurship from the state and its targeted use.

The specificity of the development of social entrepreneurship in Russia is on the provision of social services. State structures mainly carry out the solution of social problems within the framework of existing competencies and legislation. At the same time, in Russia there are stable niches for social entrepreneurs, which are created as a result of a slow response, imperfect legislation, and the sluggishness of state bodies to emerging social problems, which is often characteristic of municipal structures, therefore the need and demand for such types of small business activities aimed at solving social problems remain relevant [4].

The development of social entrepreneurship in Russia takes place in a different institutional environment since the socio-economic development of the regions of Russia is not homogeneous. Identifying contextual conditions and other features that have a beneficial effect or hinder the development of social entrepreneurship is an important research question. Our previous scientific work shows that the institutional environment, both formal and informal, is an essential factor in developing entrepreneurship in various countries and regions of the world [4]. In addition, previous studies have shown that digitalization has a significant impact on the development of social entrepreneurship at the country level at the stage of operational activities and is a driver for accelerating business processes [4].

In current conditions, the penetration of new digital technologies into all spheres of human life has become a key trend in economic development. The use of digital solutions today is moving from the category of radical innovations into an everyday routine. Digital technologies have already found their application at the state, business, and even household levels. To accelerate the digitalization processes in the Russian Federation, the program "Digital Economy of the Russian Federation" was adopted and is being implemented. The digitalization of public institutions and organizations (hospitals, tax services, registration chambers, etc.) and, accordingly, the receipt of public services online is being implemented quite effectively [11].

Digitalization as a modern trend affects most economical processes, including social entrepreneurship. The availability of an appropriate digital-physical infrastructure provides social entrepreneurship with the necessary resources and supports its development. In 
addition, digitalization provides companies with opportunities to enter new markets, expand customer base and open up opportunities for innovative activities, including creating digital products, services, and business models called digital entrepreneurship. Fast digital adaptation plays a crucial role in increasing income and social satisfaction [6]. Similarly, digital technologies play an essential role in the development of society, providing easy access to public services, higher employment, and more significant economic growth, which inevitably leads to increased welfare [7]. Although digital technology significantly impacts the entrepreneurial process, research on its use is still limited. In addition, in the scientific literature, the methodological basis for studying this phenomenon is not sufficiently developed, especially at the level of Russia, which can be explained by the lack of observations and statistical data. This limitation does not allow quantitative analysis of this phenomenon. Moreover, the scientific literature does not sufficiently disclose the contradictions of social entrepreneurship, the connection of this phenomenon with digitalization, and modern interaction methods between economic agents.

The role of digitalization, as an important condition for the development of the institutional environment, is due to its ability to reduce transaction costs, accelerate obtaining the necessary information, ensure the mobility of resources, and the emergence of new support methods. Scientific works on this topic [8] demonstrate the relevance of research investigating the role of digitalization in creating socio-economic change. The rise of digital technologies has led to changes in entrepreneurship and opened up new opportunities in terms of increasing productivity, creating added value, and developing new ways of interaction between economic agents. At the same time, as H. Prodanov shows, the digitalization processes and, accordingly, the fourth industrial revolution give rise to a set of social problems, which by now, although not fully manifested, may be exposed in the near future. The list of these problems includes the growth of social inequality, the reduction of jobs, the decline of the middle class, etc.[12]

This study aims to determine the impact of the level of digitalization in the region on the development of social entrepreneurship in this region.

The development of social entrepreneurship is closely related to the acceleration of socio-economic and technological processes caused by an increase in the speed of data exchange and digital transformation in general. Digital information technologies are becoming the most important economic resource and have a dominant impact on economic relations [6]. At the same time, the development of digitalization requires serious investment from the state to provide access to high-speed Internet, including mobile. For many companies, this infrastructure element is vital, thanks to which it gives the ability to access information resources, continuous interaction with contractors, and product placement.

Thus, we put forward the following hypothesis:

Hypothesis 1. The volume of investments in informatization and communications stimulates the development of social and entrepreneurial activities in the regions of the Russian Federation.

The introduction of digital technologies into socio-economic processes initiated the transformation of institutions, which was reflected in the increase in the importance of social networks, the level of trust, and other factors in the implementation of social and commercial projects. Since social entrepreneurship, as a rule, interacts with private households and solves the problems of this particular category of the population, an essential factor influencing the development of this type of activity is access to quick information acquisition and implementation of the required communications. In this context, the availability of the Internet and the use of personal computers by private households can significantly impact the emergence of social entrepreneurship, providing 
the formation and consolidation of rules and regulations that stimulate the development of this type of activity. Internet access enables people to consume new products through online stores, place new products, etc. In this regard, the following hypothesis was formulated:

Hypothesis 2. The prevalence of Internet used by the population in the region has a positive impact on social entrepreneurship in the region.

\section{Research methodology and Data}

The information base of the study was the statistical data of the Analytical Department of the Office of the Federation Council on the number of registrations of socially-oriented organizations in various regions of the Russian Federation in the first wave of 2020. Since the legislation in the Russian Federation on social entrepreneurship was adopted only in 2019 , at the end of 2021 , this is the only statistical data characterizing the level of social entrepreneurship at the regional level.

As independent variables, we used Rosstat data on investments in fixed assets in 2019 for informatization and communications in various regions of the Russian Federation. The structure of fixed-assets investments includes costs incurred at the expense of citizens and legal entities and other attracted organizations [5].

To determine the percentage of the population using the Internet in regions of the Russian Federation, we used Rosstat data for 2019.As a result of the analysis, 59 regions were obtained with a dependent and independent variable.

Table 1. Results of regression analysis.

\begin{tabular}{|c|c|}
\hline \multicolumn{2}{|c|}{ Regression statistic } \\
\hline Multiple R & 0,559519 \\
\hline R Square & 0,313061 \\
\hline Adjusted R Square & 0,288528 \\
\hline Standard Error & 36,72383 \\
\hline Observations & 59 \\
\hline
\end{tabular}

Table 2. ANOVA analysis.

\begin{tabular}{|c|r|c|c|c|c|}
\hline \multicolumn{2}{|l|}{ ANOVA } & & & \\
\hline \multicolumn{2}{|r|}{$d f$} & SS & MS & $F$ & Significance F \\
\hline Regression & 2 & 34418,75 & 17209,38 & 12,7605426 & $2,7146 \mathrm{E}-05$ \\
\hline Residual & 5 & & & & \\
\hline Total & 5 & 75523,83 & 1348,64 & & \\
\hline
\end{tabular}

Table 3. Description.

\begin{tabular}{|l|r|r|r|r|l|r|r|c|}
\hline & Coefficient & St. error & t Stat & $\begin{array}{l}\text { P- } \\
\text { value }\end{array}$ & $\begin{array}{l}\text { Lower } \\
95 \%\end{array}$ & $\begin{array}{l}\text { Upper } \\
95 \%\end{array}$ & $\begin{array}{l}\text { Lower } \\
95 \%\end{array}$ & $\begin{array}{c}\text { Upper } \\
95 \%\end{array}$ \\
\hline & & 78,8664 & 2,505 & 0,0151 & 355,620 & 39,643 & 355,62 & \\
& & 1 & 91 & 46316 & 6792 & 9 & 1 & $-39,6439$ \\
\hline & $-197,632$ & 0,00138 & 3,224 & 0,0021 & 0,00169 & 0,0072 & 0,0016 & \\
X 1 & 0,004478 & 9 & 811 & 05443 & 6253 & 6 & 96 & 0,00726
\end{tabular}


Continuation of table 3 .

\begin{tabular}{|r|r|r|r|r|r|r|r|r|}
$\mathrm{X} 2$ & 2,578396 & 0,95758 & 2,692 & 0,0093 & 0,66012 & 4,4966 & 0,6601 & 4,49666 \\
\hline
\end{tabular}

\section{Results}

In building the model, a preliminary analysis of the initial statistical data was carried out. The most appropriate type of functional relationship between the economic processes under consideration was identified. At the second stage, a correlation analysis of the studied factors was done, making it possible to determine whether the model contains elements that form multicollinearity. At the third stage, the regression model was built directly; on the fourth, a study of the quality of the constructed model was carried out. The fifth stage included checking and eliminating autocorrelation of residuals in the model and checking for heteroscedasticity.

With the help of correlation-regression analysis, a linear one-factor model was built that determines the dependence of the development of social entrepreneurship on the financing of the digitalization sphere in the regions of the Russian Federation, expressed by the following formula:

$$
\mathrm{Y}=-197,63+0,004 \mathrm{X}_{1}+2,57 \mathrm{X}_{2}
$$

$\mathrm{Y}$ - is the number of social entrepreneurship organizations.

$X_{1}$ - investments to informatization and communication in the region for 2019 .

$\mathrm{X}_{2}$ - the share of the population in the region using the Internet.

\section{Discussion}

Confirmation of Hypothesis $\mathrm{H} 1$ indicates that the potential of digital development in the region, expressed in attracting funds to fixed assets for its improvement, has a beneficial effect on the overall economic performance in the area in general and social entrepreneurship in particular. Thus, in the most actively developing regions in the context of digital transformation, social entrepreneurship has more chances for successful functioning and scaling, since social entrepreneurs have more opportunities to sell their goods and services and attract financial resources, including through crowdfunding and crowdfunding platforms.

Crowdacting is "coordinated, conditional, collective action to achieve a positive social and/or environmental goal" 1 . Within the framework of this tool, we are talking about investing their efforts in various forms. The term was first used in 2015 by CollAction, a non-profit organization that created the world's first official crowdfunding platform (www.collaction.org). Crowdacting develops if three conditions are met: 1) clarity of purpose; 2) orientation towards social and environmental goals; 3 ) joint action. The use of crowdacting at the project development stage also shows the project's importance for the potential audience participating in this type of activity. In this case, the mechanism of coercion changes. The motivation for action is the importance of solving this problem and collective participation, which is a source of resources and support in the possibility of realizing a particular goal.[10]

As a result, the confirmation of $\mathrm{H} 2$ is due to the availability of the Internet and its quality among the region's population as the main consumer of social services.

With regard to considering the impact of digitalization in the regions of the Russian Federation on the development of social entrepreneurship, it is also necessary to refer to our previous studies showing that for the emergence and development of this type of 
activity, a high level of post-materialistic values in society related to issues of civil liberties and ecology is required [6]. Information and communication technologies and the availability of Internet access among households, in turn, serve as an additional tool for its development.

\section{Conclusion}

This study contributes to a better understanding of the roles of digitalisation and social entrepreneurship. In this study, to analyze and substantiate the impact of digitalization processes on the development of social entrepreneurship using the example of the regions of the Russian Federation, the following results were obtained.

Firstly, digitalization and its impact on social and entrepreneurial activity are considered from the point of view of investments, that is, the digital potential of the region. On the other hand, an effective indicator is used: the prevalence of the Internet among the population. Secondly, it is determined that digitalization has a positive impact on social entrepreneurship.

Based on the example of analyzing the experience of developing social entrepreneurship in Russia, it was determined that the digital transformation of the institutional environment, namely: improving the digital infrastructure, speed, and quality of communication, as well as the prevalence of Internet use among the population, has a positive impact on the development of socially-oriented enterprises.

The theoretical significance of the results obtained lies in identifying the patterns of development of social entrepreneurship, taking into account the digital component in various regions of the Russian Federation. The practical significance lies in substantiating the importance of digitalization to stimulate the development of social entrepreneurship.

This research is not without limitations, such as the number of regions in the sample. The number of observations is limited by the data sources, which are based on statisitc. The sample size also limits the number of conditions that can be included in the analysis since the model should be parsimonious and non-redundant. Future studies could overcome these limitations using different datasets. The convergence of digital and entrepreneurship requires new studies to clarify the impact of digitalization. For example, future studies could examine the effects of digitalisation on entrepreneurs' subjective well-being and nonformal institutional environment.

\section{Acknowledgements}

The study was supported by the Russian Foundation for Basic Research, project No. 20010-00333.

\section{References}

1. A. Moskovskaya, I. Soboleva, Social entrepreneurship in the system of social policy: International experience and prospects of Russia, Studies on Russian Economic Development, 27, 683-688 (2016)

2. K. Alter, Social Enterprise Typology, Virtue Ventures LLC (2007)

3. T. Ilushnikova, About the role of social entrepreneurship in the social sphere of Russian Federation Analytics (2021) 
4. E. Popov, A. Veretennikova, I, Naumov, K. Kozinskaya, Non-formal institutional environment of social entrepreneurship, Economic and Social Changes: Facts, Trends, Forecast, 11(4), 217-234 (2018)

5. Russian Federaition Regions. Socio-economic indicators (2019). Access mode: https://rosstat.gov.ru/storage/mediabank/1dJJCOvT/Region Pokaz 2019.pdf

6. D. Audretsch, E. Lehmann, S. Paleari, S. Vismara, Entrepreneurial finance and technology transfer, 41 (1), 1-9 (2009)

7. J. Dong, Moving a mountain with a teaspoon: toward a theory of digital entrepreneurship in the regulatory environment Technol, Forecast. Soc. Change, 146, 923-930 (2019)

8. M.-Á. Galindo-Martín, M.-S.Castaño-Martinez, M.-T. Méndez-Picazo, Digital transformation, digital dividends and entrepreneurship: a quantitative analysis, 101, 522-527 (2019)

9. P. Gupta, S. Chauhan, J. Paul, M. Jaiswal, Social entrepreneurship research: a review and future research agenda, 113, 209-229 (2020)

10. B. Hoogendoorn, The prevalence and determinants of social entrepreneurship at the macro level, J. Small Bus. Manag, 54, 278-296 (2016)

11. U. Stephan, L. Uhlaner, C. Stride, Institutions and social entrepreneurship: the role of institutional voids, institutional support, and institutional configurations, J. Int. Bus. Stud., 46 (3), 308-331 (2015)

12. H. Prodanov, Social Enterpreneurship And Digital Technologies, Economic Alternatives, 1, 123-138 (2018) 